\title{
Gallbladder Neck
}

National Cancer Institute

\section{Source}

National Cancer Institute. Gallbladder Neck. NCI Thesaurus. Code C32649.

The narrowest portion of the gallbladder and distal to the cystic duct. 